\title{
Occupational asthma due to a widely used soft solder flux not containing colophony
}

\author{
R.P. Convery, R.J. Ward, D.J. Hendrick
}

Occupational asthma due to a widely used soft solder flux not containing colophony. R.P. Convery, R.J. Ward, D.J. Hendrick . CERS Journals Ltd 1997.

ABSTRACT: A 19 year old woman presented with symptoms suggestive of occupational asthma. The causative agent was thought to be a soft solder flux, which did not contain colophony.

The diagnosis was established by specific inhalation challenge tests, which demonstrated both late asthmatic reactions and short-lived increases in airway responsiveness.

Eur Respir J., 1997; 10: 238-240.
Dept of Respiratory Medicine and Regional Unit for Occupational Lung Disease, Newcastle General Hospital, University of Newcastle upon Tyne, UK.

Correspondence: D.J. Hendrick, Dept of Respiratory Medicine, Newcastle General Hospital, Westgate Road, Newcastle upon Tyne, NE4 6BE, UK

Keywords: Asthma, occupation, solder flux Received: April 27 1995; accepted after revision August 181996
The Surveillance of Work-related and Occupational Respiratory Disease (SWORD) project has monitored newly recognized cases of occupational lung disease in Britain since its inception in 1989 [1]. It has noted over 500 new cases of occupational asthma per year, representing 25-30\% of all occupational lung disease. Asthma attributable to the fumes of colophony (a soft solder flux derived from pine resin) has been one of the major types of asthma reported to SWORD, and has accounted for about $6 \%$ of the asthma cases. It was first recognized in 1976 [2]. TELUX® is one of several soft solder fluxes specifically designed and commercially produced as a "safe" alternative to colophony. It is widely-used in industry, and contains ammonium and zinc chlorides in a paraffin wax and mineral oil base.

\section{Case report}

A 19 year old nonsmoking woman was employed as a gas appliance servicing engineer. She had previously been fit and active with no personal history of asthma, but her father and brother had histories of hay fever and childhood asthma, respectively. Between 19901993, she was an apprentice with minimal flux fume exposure (approximately 1 day in 50), but from September 1993 she obtained a fulltime post, which involved daily TELUX® fume exposure of 1-3 h. After 10 weeks, she developed episodes of mild chest tightness, culminating in quite severe respiratory distress when she developed a viral-type chest infection during a holiday weekend. A local physician diagnosed asthma and prescribed a bronchodilator inhaler. By chance her work pattern then changed and she worked with TELUX ${ }^{\circledR}$ only sporadically and for short periods. On such days, she noticed dyspnoea and chest tightness on exertion, but was never unduly distressed.
She was referred by her company physician in February 1994, when ventilatory and parenchymal function were normal (forced expiratory volume in one second (FEV1) $4.47 \mathrm{~L} ; 121 \%$ of predicted value). A standardized methacholine test was performed and the provocative dose producing a $20 \%$ fall in FEV1 (PD20) was only $10 \mu \mathrm{g}$. This indicates a high degree of airway responsiveness, and is consistent with active asthma [3]. The patient was then removed from all occupational exposures of possible relevance. Not only did symptoms disappear but PD20 increased to $>1,000 \mu \mathrm{g}$ methacholine, when remeasured 5 months later. A value such as this is almost never associated with active asthma.

\section{Inhalation challenge tests}

The patient underwent two laboratory-based inhalation challenge tests, during which her usual work practices with TELUX ${ }^{\circledR}$ were reproduced as closely as possible. Because her usual occupational exposures were for 1-3 h daily, an initial challenge was planned with a 30 min exposure followed, if necessary, by challenge exposures on separate days of 1,2 and $4 \mathrm{~h}$, sequentially.

FEV1 was monitored at $10 \mathrm{~min}$ intervals for $30 \mathrm{~min}$ before and 90 min after challenge onset, during which the patient was observed closely. She then measured FEV1 hourly herself for the period $2-12 \mathrm{~h}$ after challenge, throughout which phone contact was readily available with the supervising physician. For 3 days before the challenge tests, she measured FEV1 hourly at home in order to produce control data. From these, the mean FEV1 at each hour was calculated and plotted, together with the "pooled" lower 95\% confidence limit (95\% CL) [4]. In addition, the "FEV1 area above the curve" from 2-12 h after challenge (area decrement) was calculated 
as a summary measure for any late change in ventilatory function [4]. This method of analysis is complementary to serial measurements of FEV1, but is more responsive to any variability in daily baseline FEV 1 because the area decrement is bounded by the extrapolated mean FEV1 over the 30 minutes before the time of challenge each day. PD20 was measured before and after the challenge sequence.

\section{Results}

With the 30 min soldering challenge, we observed a $25 \%$ fall in FEV1 from baseline, but this did not quite breach the lower 95\% CL (fig. 1), nor did the patient note any symptoms. There was, however, a significant $(\mathrm{p}<0.01)$ increase in the $2-12$ hour area decrement $(+4.9$ $\mathrm{L} \cdot \mathrm{h}$ versus a mean control value of $0.06 \mathrm{~L} \cdot \mathrm{h}, 95 \%$ confidence interval $(95 \% \mathrm{CI})-1.2$ to $+1.3 \mathrm{~L} \cdot \mathrm{h})$. Three weeks later, a $60 \mathrm{~min}$ challenge produced much more conclusive results. An immediate asthmatic response extended into a sustained late asthmatic response, which had not completely resolved some $22 \mathrm{~h}$ postchallenge (fig. 1 ). The FEV1 fell maximally by $58 \%$ from the baseline level but only mild-to-moderate symptoms were noted, which did not require relief bronchodilators.

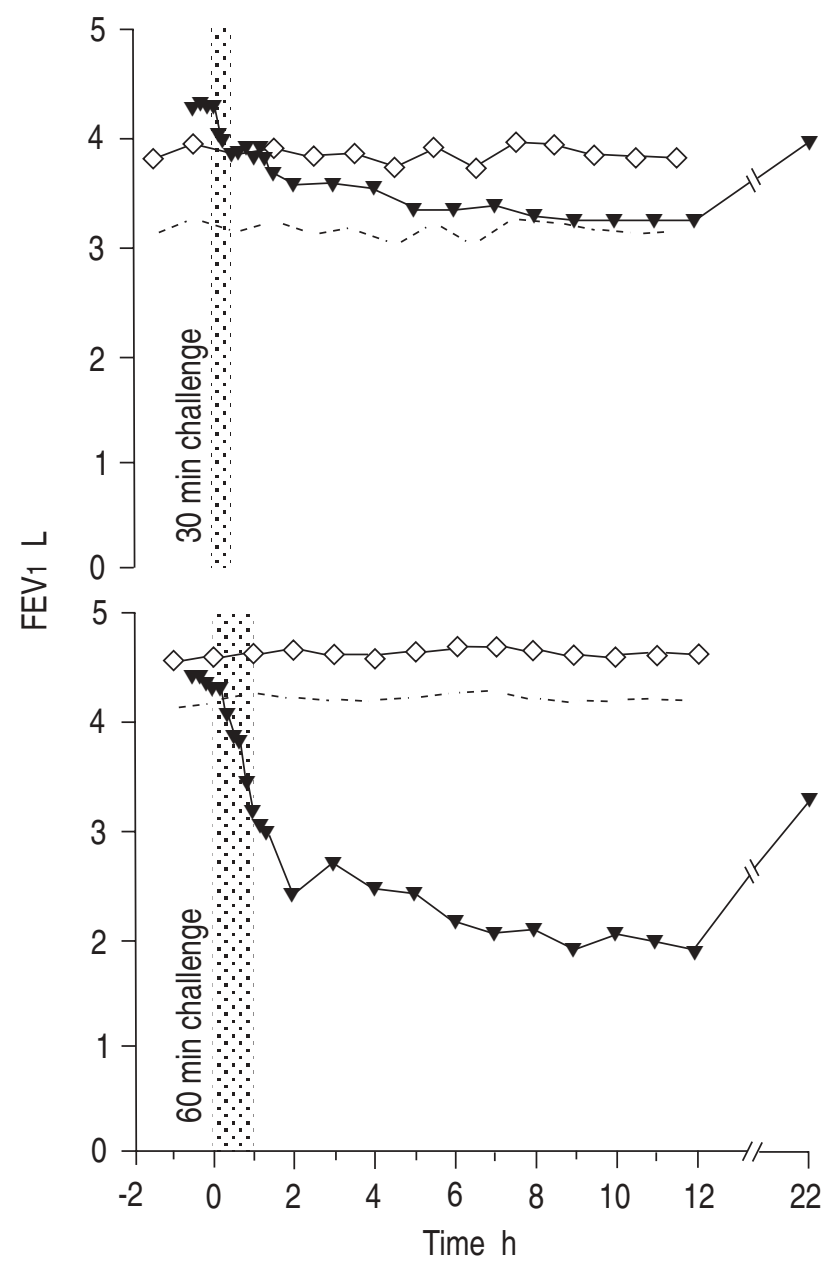

Fig. 1. - Forced expiratory volume in one second (FEV1) profiles for the 30 and 60 min challenges. $\longrightarrow$. Telux $₫ ; \diamond-$ : control mean; ---o-.- : 95\% lower confidence limit.

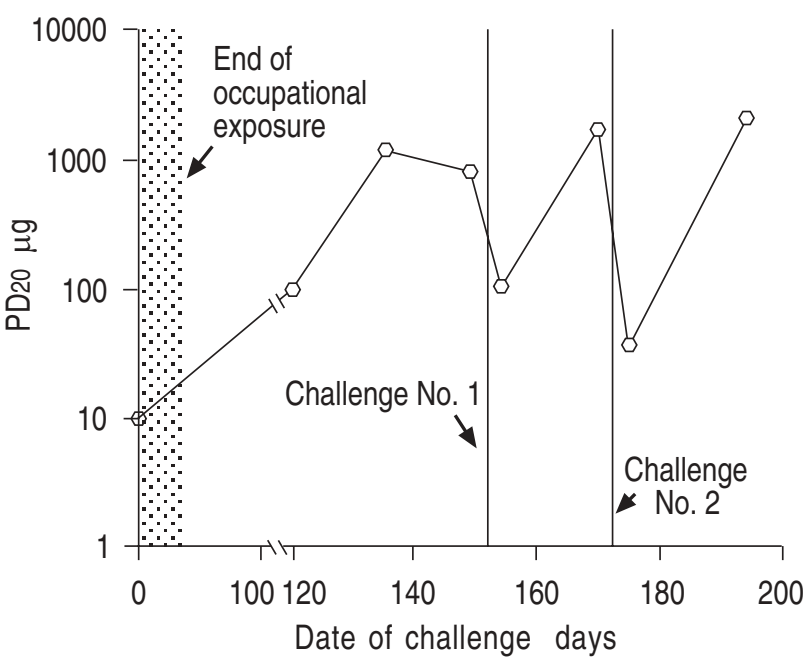

Fig. 2. - Serial methacholine PD20 measurements. PD20: provocative dose of methacholine producing a $20 \%$ fall in forced expiratory volume in one second.

There was a parallel significant $(\mathrm{p}<0.001)$ increase in 2-12 h FEV1 area decrement $(+21.5 \mathrm{~L} \cdot \mathrm{h}$ versus a mean control value of $0.03 \mathrm{~L} \cdot \mathrm{h}, 95 \% \mathrm{CI}-2.9$ to $+2.8 \mathrm{~L} \cdot \mathrm{h})$.

Serial measurements of PD20 are shown in figure 2 . A decrease to less than one third of the prechallenge value has been shown to be significant [3], and this was observed in association with both challenge tests.

\section{Discussion}

The combination of asthmatic symptoms, a late asthmatic reaction and increased airway responsiveness clearly implicates TELUX® solder flux as a cause of occupational asthma. Since diagnosis, the patient has moved within the same company to a job without further exposure and has remained symptom-free. The dramatic changes in PD20 over a matter of days are notable, and are characteristic of occupational asthma in its emergent stages [5].

Colophony and noncolophony fluxes are widely used in industry. As far as we know, this is the first documented case of occupational asthma due to TELUX® soft solder flux, although WEIR et al. [6] have described two similar cases attributable to a soft solder flux containing zinc and ammonium chlorides but not colophony. The manufacturer and the precise composition of this solder flux are not known (PS Burge, personal communication). These authors postulated that an abnormal chloride ion load in the bronchial wall may affect smooth muscle tone in much the same way that increased dietary salt is said to increase airway responsiveness. The postulated relationship between sodium chloride and airway responsiveness remains controversial, however, and we suspect that the causative agent within TELUX® solder flux lies within the zinc or mineral oil components.

\section{References}

1. Meredith SK, Taylor VM, McDonald JC. Occupational respiratory disease in the United Kingdom, 1988: a 
report to the British Thoracic Society and the Society of Occupational Medicine by the SWORD project group. Br J Ind Med 1991; 48: 292-298.

2. Fawcett IW, Newman Taylor AJ, Pepys J. Asthma due to inhaled chemical agents: fumes from "multicore" soldering flux and colophony resin. Clin Allergy 1976; 6: 577-585.

3. Beach JR, Young CL, Avery AJ, et al. Measurement of airways responsiveness to methacholine: relative importance of the precision of drug delivery and the methods of assessing response. Thorax 1993; 48: 239-243.
4. Stenton SC, Avery AJ, Walters EH, Hendrick DJ. Statistical approaches to the identification of late asthmatic reactions. Eur Respir J 1994; 7: 806-812.

5. Convery RP, Bourke SJ, Stenton SC, Hendrick DJ. Marked and rapid changes in airway responsiveness in early occupational asthma. Eur Respir J 1995; 8 (Suppl. 18): $193 \mathrm{~s}$

6. Weir DC, Robertson AS, Jones S, Burge PS. Occupational asthma due to soft corrosive soldering fluxes containing zinc chloride and ammonium chloride. Thorax 1989; 44: 220-223. 